\section{SEASONAL VARIATION OF LUNG FUNCTION AMONG COFFEE WORKERS EXPOSED TO BIO-AEROSOLS IN TANZANIA}

${ }^{1} \mathrm{G}$ Sakwari ${ }^{*},{ }^{1} \mathrm{~S}$ Mamuya, ${ }^{1} \mathrm{~V}$ Ngowi, ${ }^{2} \mathrm{M}$ Bratveit, ${ }^{2} \mathrm{~B}$ Moen. ${ }^{1}$ Muhimbili university of Health and Allied Sciences, Environmental and Occupational Health, Dar es Salaam Tanzania; ${ }^{2}$ University of Bergen, Department of Global Public Health and Primary Care, Bergen, Norway

\subsection{6/oemed-2018-ICOHabstracts.1313}

Introduction Exposure to organic dust may lead to decrease in lung function among healthy subjects or development of respiratory symptoms. Studies done among coffee workers reported significant exposure to endotoxins with no evidence of decrease in lung function. The current study aimed at determining seasonal variation of lung function among coffee workers due to endotoxin exposure.

Methods The study was done in coffee factory where 30 workers were monitored for one season of coffee processing that is from June 2016 to February 2017. Lung function tests were performed once in the morning on any day before the season, then on Monday morning and Friday evening at midseason and end of the season. A portable spirometer WinspiroLIGHT was used. ATS/ERS guidelines were followed. All measurements were taken in standing position. Data was analysed by paired-sample T-test. Smoking and age used to adjust lung function change in linear regression.

Results The mean age of participants was 38 (8.4) and mean time of working in coffee factories was 10 (6.8) years. There was a significant decrease of 24 and $20 \mathrm{mls}$ for $\mathrm{FEV}_{1}$ and FVC, the change being high in the mid-season compared to end season. Improved in $\mathrm{FEV}_{1}(3.29 \mathrm{l} / \mathrm{s}-3.65 \mathrm{l} / \mathrm{s})$ at the beginning of season to mid-season was observed.

Discussion Lung function decrease is observed along the season with higher decrease at the end of season. The slight increase in $\mathrm{FEV}_{1}$ between beginning of season and mid-season could be due to cessation of exposure.

\section{Rural Health: Agriculture, Pesticides and Organic Dusts}

\section{SAFETY CULTURE AND RISK MANAGEMENT IN AGRICULTURE (SACURIMA)}

${ }^{1} J o h n$ Mc Namara*, ${ }^{2}$ Jarkko Leppälä, ${ }^{3}$ Gert van der Laan, ${ }^{3}$ Claudio Colosio, ${ }^{4}$ Martina Jakob, ${ }^{5}$ Stephan Vander Broucke, ${ }^{6}$ Laura Girdziute, ${ }^{7}$ Eda Merisalu, ${ }^{8}$ Anne Marie Heiberg, ${ }^{2}$ Risto Rautiainen. ${ }^{1}$ Teagasc, Ireland; ${ }^{2}$ National Resources Institute, Luke, Finland; ${ }^{3}$ International Centre for Rural Health, University of Milano, Italy; ${ }^{4}$ Leibnitz Institute for Agricultural Engineering, Germany; ${ }^{5}$ University of Leuven, Belgium; ${ }^{6}$ Aleksandras Stulginskis university, Lithuania; ${ }^{7}$ Estonian University, Tartu, Latvia; ${ }^{8}$ University of Agder, Norway

\subsection{6/oemed-2018-ICOHabstracts. 1314}

Introduction Agriculture is one of the most hazardous industries in Europe, measured by work-related injuries, diseases, disabilities and deaths. Statistics and studies show great differences in national injury and occupational disease rates, as well as approaches and support for prevention of these adverse outcomes. This EU-COST action explores reasons why agriculture lags behind other sectors, and why some countries have been more successful than others in reducing agricultural injuries and diseases.

Methods
1. Evaluation of health and safety programmes and approaches on the national level

2. identification of knowledge, attitudes, behaviors and priorities among farmers regarding safety, health and risk management

3. identification of effective measures for training and integrating vulnerable populations (including refugees) into the agricultural workforce

4. development of indicators for monitoring progress and evaluating the impact of interventions on occupational injuries and diseases in agriculture.

Results Benchmarked and evidence-based recommendations will be developed to inform and guide national initiatives and efforts. Results will be disseminated to stakeholders and the agricultural community.

Discussion This action is in progress; previous Cooperation in Science and Technology (COST) Actions, like Monitoring Occupational Diseases and tracing New and Emerging Risks in a Network (MODERNET) show that such multidisciplinary, international focused exchange programmes are effective to trigger awareness raising and preventive actions.

\section{KNOWLEDGE LEVEL, ATTITUDE AND BEHAVIOR OF FARMERS IN THE ÇUKUROVA REGION ABOUT THE USE OF PESTICIDES}

${ }^{1}$ Dilek Öztaş, ${ }^{2}$ Burak Kurt, ${ }^{3}$ Ayşegül Koç, ${ }^{2}$ Muhsin Akbaba*, ${ }^{4}$ Hüseyin Ilter. ${ }^{1}$ Department of Public Health, YIldirm Beyazıt University School of Medicine, Ankara, Turkey; ${ }^{2}$ Department of Public Health, Çukurova University School of Medicine, Adana, Turkey; ${ }^{3}$ Department of Internal Medicine Nursing, YIldirm Beyazıt University Faculty of Health Sciences, Ankara, Turkey; ${ }^{4}$ Public Health General Directorate of Turkish Republic, Ankara, Turkey

\subsection{6/oemed-2018-ICOHabstracts. 1315}

Introduction There are concerns about safety culture and health effects of pesticides in agricultural workers in the Adana Province of Turkey. The aim of this study is to evaluate knowledge level of farmers in the Çukurova region on the health effects of pesticides, use of protective equipment as well assessment of attitudes and practices about the use of pesticides.

Methods A total of 420 seasonal agricultural workers in Karataş District of the Province of Adana Turkey were included in the study. The questionnaire was administered using face-toface interview method.

Results The mean age of the participants was $40.2 \pm 10.6$ years, engaged in farming for a mean duration of $18.5 \pm 10.6$ years. All were applicating pesticides, but none had been trained in the safe use of pesticides. Concerning working practices and health aspects:

- $26.2 \%$ stored pesticides in a secured depot.

- $4.3 \%$ took empty pesticide containers to special collection bins or centers.

- $84.0 \%$ thought that pesticides could have a negative impact on human health.

- $5.0 \%$ experienced a medical problem after application of pesticides.

- $1.0 \%$ reported acute poisoning after applying pesticides.

Discussion The knowledge level of agricultural workers about safe use of pesticides in this study population is very poor. This lack of knowledge adversely affects occupational health and safety. Appropriate training programs will be organized to increase their level of knowledge. 